\title{
EXPERIENCES OF THREE LANDFILL MINING PROJECTS IN THE BALTIC SEA AREA \\ - with focus on machinery for material recovery
}

\author{
Marika Hogland ${ }^{1}$ \\ William Hogland ${ }^{1}$ \\ Yahya Jani ${ }^{1}$ \\ Fabio Kaczala ${ }^{1}$ \\ André Luís de Sá Salomão² \\ Mait Kriipsalu ${ }^{3}$ \\ Kaja Orupõld ${ }^{3}$ \\ Juris Burlakovs ${ }^{4}$ \\ ${ }^{1}$ Linnaeus University, Sweden \\ ${ }^{2}$ Rio De Janeiro State University, Brazil \\ ${ }^{3}$ Estonian University of Life Science, Estonia \\ ${ }^{4}$ Geo-IT, Latvia
}

\begin{abstract}
There exists huge number of old landfills and dumps located close to the rivers and lakes in the Baltic Sea Region as well as the Baltic Sea itself. The main risks from landfills are water pollution from leachate and global greenhouse effect from methane emissions as well as effects on human health. Landfill excavation and land remediation are potential methods for treatment of waste from old landfills. Excavation of a landfill might be interesting in order to recover valuable materials from the landfill, save cost for final coverage of the landfill and aftercare. The research project "Closing the Life Cycle of Landfills - Landfill Mining in the Baltic Sea Region for future" sponsored by the Swedish Institute includes studies of excavations of landfills in Baltic Sea Region. It is well known, that landfills contribute to a major extent in the dumping of hazardous substances and the reclamation of such landfills is essential for the sustainable development of the environment. Through the approach used solutions for the remediation/prevention of water and soil pollution and for land reclamation is shown. The resource recovery is one of the beneficial areas of generating revenue for the success of excavation projects. In present paper three landfill mining excavations are presented and in particular with focus on the machinery used. The full-scale excavation is presented from the Estonian Kudjape Landfill, Högbytorp landfill and Vika landfill in Sweden.
\end{abstract}

\section{KEYWORDS}

Harbor mining, landfill mining, environment, metals, toxic substances, recovery, economy. 


\section{INTRODUCTION}

In many regions of the world, landfills have long been seen as a final way to store waste at minimum cost and the most common waste disposal method (Kollikkathara et al., 2009; Krook et al., 2012). Even in countries which have developed systems for waste treatment and recycling, this option has often remained important. Nowadays, the lack of space to implement new landfills, especially in densely populated areas, became a problem to the expansion of the big cities (Zhao et al., 2007), so in some countries the landfill mining became a very good option, and it has been also considered the future of recycling and an innovative strategy to address such implications related to waste deposits (Hogland, 2002).

According to Krook et al. (2012) landfill mining could be described as a process for extracting minerals or other solid natural resources from waste materials that previously have been disposed off by burying them in the ground. According to Hogland (2002) and others, the purposes of LFM have been: (1) conservation of landfill space; (2) reduction in landfill area; (3) elimination of a potential source of contamination; (4) mitigation of an existing contamination source; (5) energy recovery; (6) recycling of recovered materials; (7) reduction in management system costs; (8) site redevelopment.

In the process, mining recovers valuable recyclable materials, including metals which currently reflect high market prices, and plastics which, although possibly heavily contaminated, could still be utilized for energy recovery and landfill space (Hogland et al., 2004). The aeration of the landfill soil is a secondary benefit regarding the landfill's future use. The overall appearance of the landfill mining procedure is a sequence of processing machines (excavators, screens, and conveyors), laid out in a functional conveyor system.

The US EPA has announced that the decontamination of sediments will receive the highest priority (Mulligan et al., 2001). Cadmium, copper, lead, mercury, nickel and zinc are considered the most hazardous heavy metals and are included on the EPA's list of priority pollutants (Mulligan et al., 2001). Some of the heavy metals can cause highly toxic and/or bio-accumulative effects and are persistent in environment and throughout food chain (Ghirişan et al 2007).

The Environmental Science \& Engineering Group (ESEG) at Linnaeus University has been together with researchers from different Baltic countries working with landfill mining during the last two years even if landfill mining started in Hoglands research group already in 1994. This paper will focus on excavation; land reclamation, resource recovery and machinery used in three landfill mining excavations within the frame of project "Closing the Life Cycle of Landfills - Landfill Mining in the Baltic Sea Region for future” 2012-2015 sponsored by the Swedish Institute.

\section{PLANNING OF EXCAVATION}

Eugene Salerni (1995) wrote a "Landfill Reclamation Manual” including the necessity to make a careful feasibility analysis including; operation history, waste types dumped, dimensions of landfill, topography, physical characteristics before starting the excavation which means a proper site investigation. A detailed work plan for the test and full-scale excavation must be compiled including number of test pits/trenches, selection of equipment, material processing system, labor organization, creation of working zones and choice of analytical testing, measurement and data collection. Health and safety is very important at the working site, involved persons have to be responsible - labour must be educated before the signing of document on safety issues. Proper protection clothes, hard hats, safety glasses, gloves, boots, masks etc. are important as well as monitoring equipment including organic 
vapor and methane meters and a full contingency plan. The planning on the site before the excavation is important, e.g., how much material of each category must be handled, stored and how the excavation should be performed. The use of the machines must be efficient with no unnecessary movements, well balanced logistics forthe waste/soil handling is highly recommended. Weather conditions must be taken in account, and capacity of labourwith right proficiency is required. Monitoring of air emissions, surface and groundwater quality must be performed..

More information on landfill mining performance is also available in: Joseph, K., Nasgendran, R., Thanasekaran, K., Visvanathan, C., Hogland, W., Kathikeyan, O., P., Moorthy, N.N., 2008. Dumpsite rehabilitation manual, Centre for Environmental Studies, Anna University, Chennai - 600025 India.

\section{THE THREE SITES EXCAVATED}

\subsection{Saaremaa landfill in Estonia}

\section{Kudjape Landfill}

Kudjape Landfill before the excavation was 5.16 ha, of which 4.2 ha was covered by waste when excavation started. Fresh dumping area was 2.7 ha, and old one 1.5 ha. Estimated amount of waste in the landfill was $193,000 \mathrm{~m}^{3}$. Kudjape Landfill had a closure plan, where landfill mining was legally foreseen as remediation measure. The expected excavation period was June-December 2011, and the proposed excavation volume was 80,000 tons which meant that the whole landfill will never be excavated completely. The excavation project started at 22.05.2012 and all works had to be finalized by 2013. The 20.09.2013 a huge celebration ceremony was held at nowadays new public sports park in the former landfill area.

Equipment as in accordance with the project plan was tested: 1) Trommel sieve $40 \mathrm{~mm}$ and 80 mm; 2) Schredder; 3) Overbelt magnet; 4) Air knife; 5) Vibrating sieve.

Wheel-frontloader (ca $1 \mathrm{~m}^{3}$ ), excavator on tracks (during high season many units of equipment worked simultaneously). Usually one shift was working but during high season two shifts were used. Main job was carried out by trommel screen $40 \mathrm{~mm}$. Some equipment used at the beginning was not accepted in the end. Mostly the magnet was not used, as it disturbed speed of a job and the output of metal was considered insufficient. The air knife was also dropped. All waste was very wet and operations of heavy vehicles made soil muddy which led distinct fraction separations time to time not possible. At the end trommel $40 \mathrm{~mm}$ was operated alone, producing $>40$ and $0-40 \mathrm{~mm}$ fractions. Wheel equipment machines experienced technical difficulties because rain made soil soft. Snow and ice made the soil slippery and when the cold weather came with temperatures down to minus $15^{\circ} \mathrm{C}$, metals were often tended to break (waste is warm, outside is cold). In total $12,257 \mathrm{~m}^{2}$ waste was excavated, and screened 57,777 $\mathrm{m}^{3}$. In Fig. 1 and 2 the machinery used at Kudjape landfill are shown. 


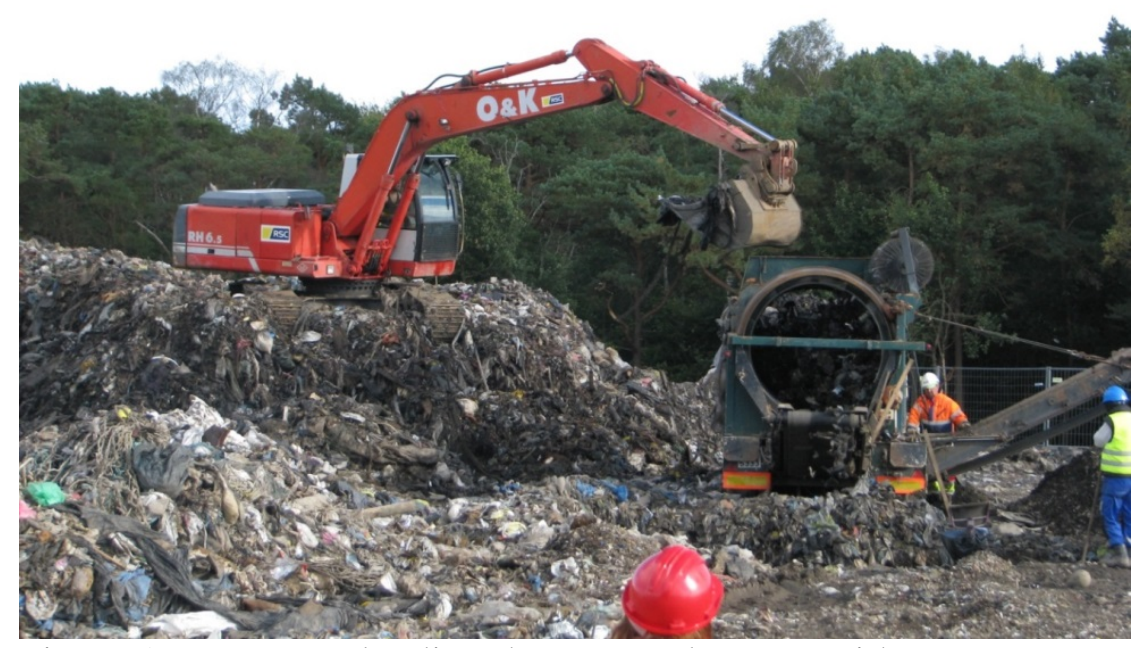

Figure 1. Excavator loading the trommel screen with waste.

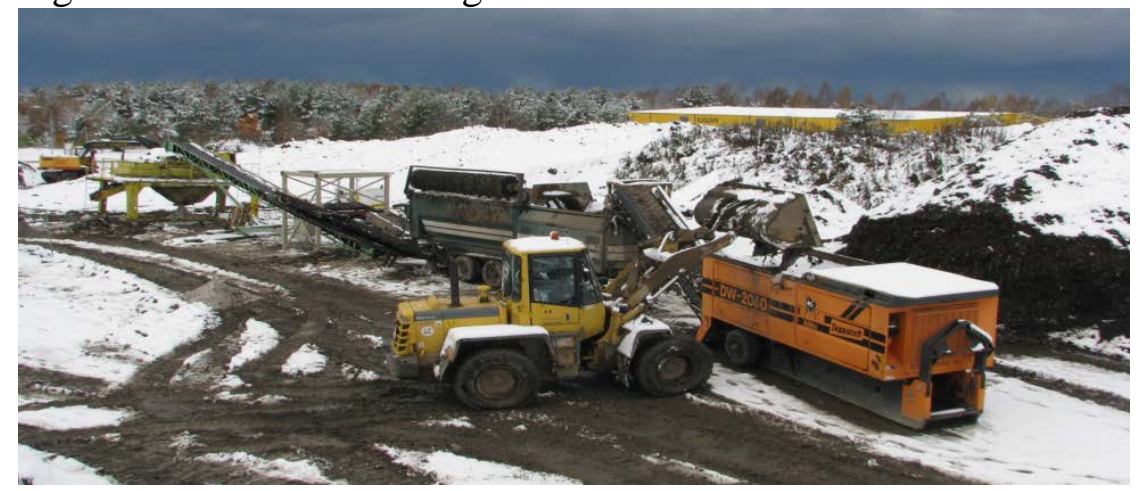

Figure 2. Equipment used at Kudjape Landfill. Front loader, pre-crushing, trommel screen and conveyor belt.

\subsection{Katrineholm landfill in Sweden}

During the field work at Katrineholm landfill, it was possible to see the complete process of separating waste in a fully mechanized through sequence machinery system. The overall machine sequence included: shredder, coarse metal separator, fine materials separator (up to $40 \mathrm{~mm}$ thickness), coarse materials separator (stones, wood pieces and others), and lightweight materials, like plastic bags (Fig. 3). 
Linnaeus ECO-TECH'14,

Kalmar, Sweden November 24-26, 2014
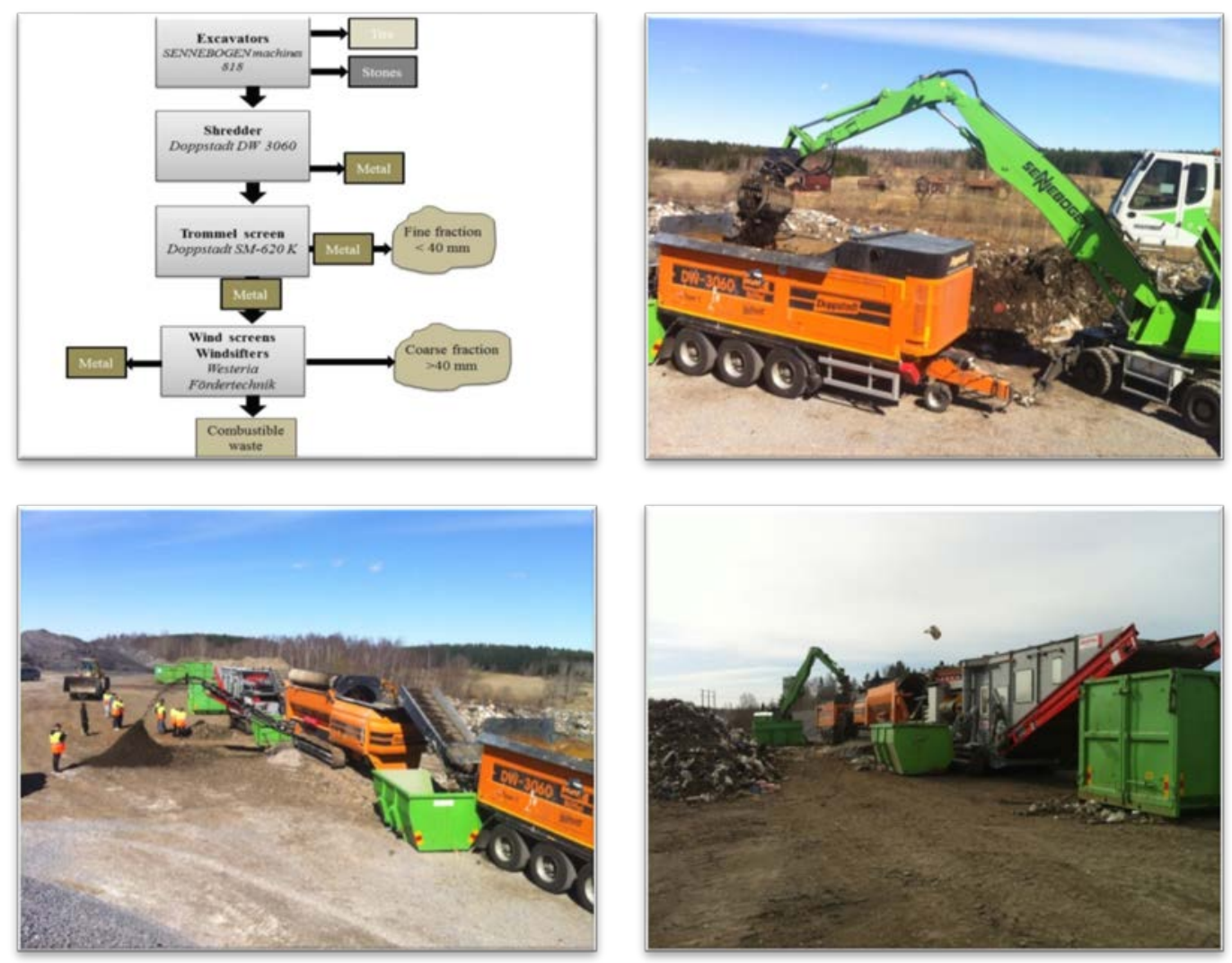

Figure 3. Mechanized process operating on landfill mining in Katrineholm landfill,

Sweden. Wind sieve, trommel sieve, pre-crushing, pre-sorting by excavator.

\section{Material and Methods}

All the piles and containers that had some material from the separator machines were sampled or collected in plastic bags or in buckets (coarse metal, fine material, coarse material and lightweight materials) (Fig. 4). With the aim to get the most homogenous samples, the fine materials pile (up to $40 \mathrm{~mm}$ thickness) was sampled in different depths and times. At the end of sampling, all the piles and containers were weighted, and the initial volume $\left(\mathrm{m}^{3}\right)$ of the mixed waste pile was calculated for the future mass balance calculations. 


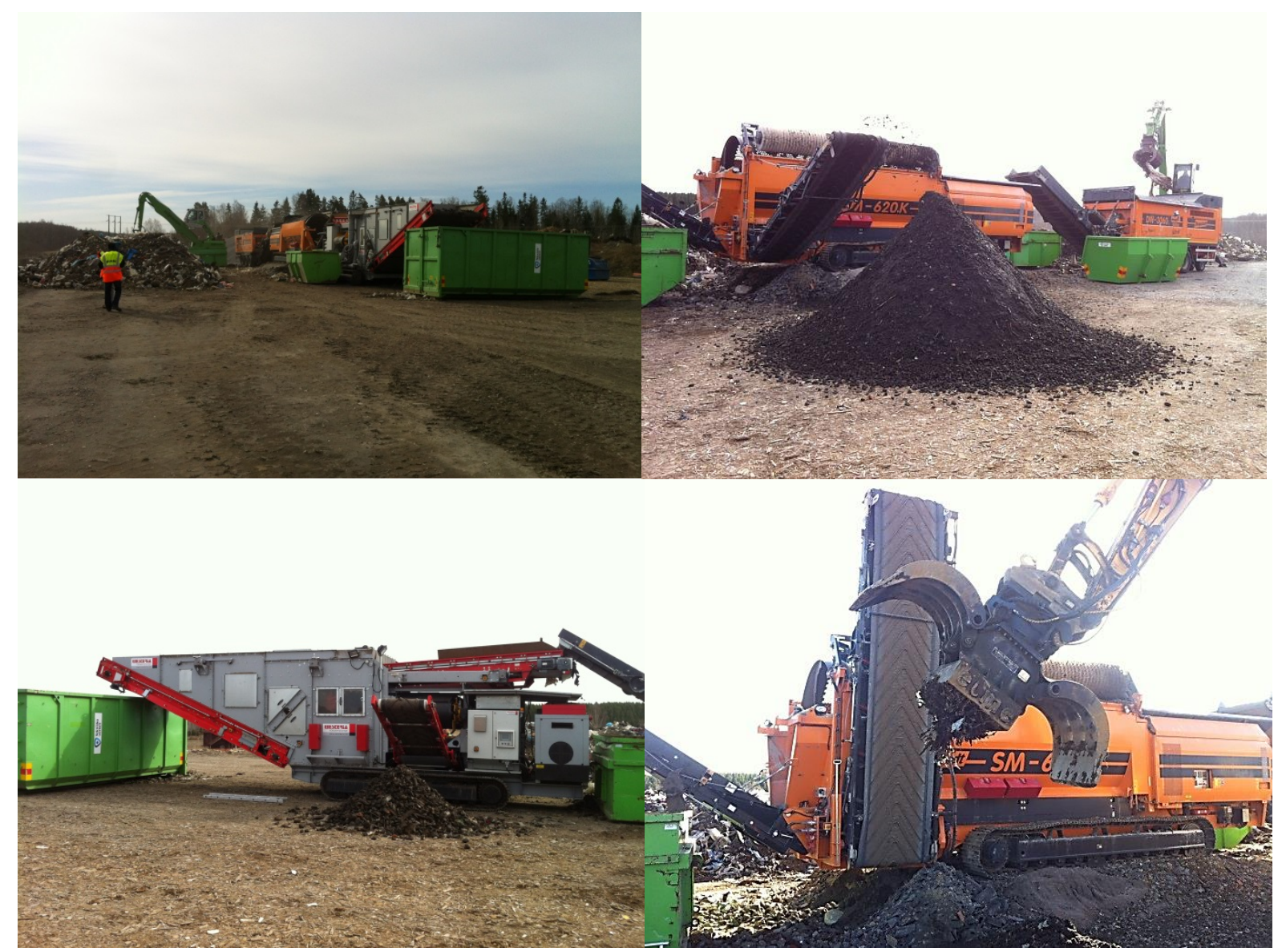

Figure 4. Initial piles with mixed waste and individual piles of the mechanic separation. Image to the right shows the magnetic separation of small pieces of metals from soil fraction.

The metal contents were analyzed with DELTA Mining \& Geochemistry Handheld XRF Analyzers (Fig. 5): fine fraction that was sampled.

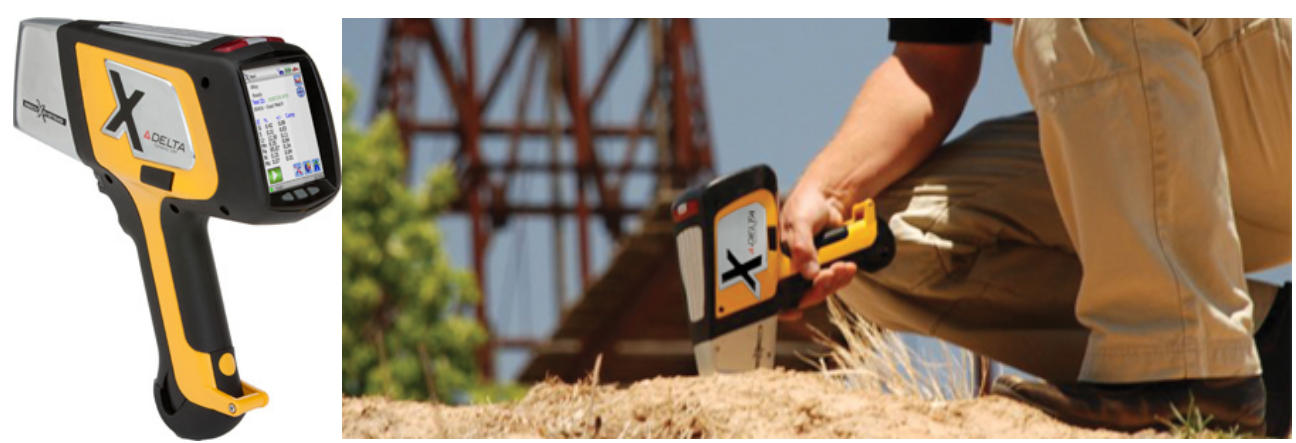

Figure 5. DELTA Mining \& Geochemistry Handheld XRF Analyzers that was used in situ to analyze the metal contents in fine material collected.

Methods for the extraction of metals in the fine fraction sampled (soil and fine materials up to $40 \mathrm{~mm}$ thickness)

According to the literature, the most common methods for the extraction of metals in soils are: chemical extraction (acids/bases, surfactants, bio surfactants, chelating agents, salts, or redox agents) to transfer the metals from the soils into an aqueous solution (Dermont et al., 2008; Mulligan et al., 2001); solidification/stabilization and washing (Mulligan et al., 2001); flotation with physical separation technique using phase specific collector (primarily $\mathrm{Cd}, \mathrm{Cu}$, 
Linnaeus ECO-TECH'14,

Kalmar, Sweden November 24-26, 2014

$\mathrm{Pb}$, and $\mathrm{Zn}$, from sediments and soils) (Dermont et al., 2008); magnetic separation of heavy metals when they are associated with the ferromagnetic materials (Dermont et al., 2008).

\section{Advantages and Disadvantages}

Physical separation

Advantages (Dermont et al., 2008): 1) Can treat organic and metal contaminants in the same treatment system; 2) By the end of the process, the contaminated soil to be further treated (for metal recovery) are considerably reduced; 3) The soil processed can be returned to the site at low cost; 4) The metal recovered may be recycled in certain cases (e.g., sent to smelting facility) or can be sold for the industry; 5) The treatment machines systems are modular and can be used on site remediation; 6) The technologies are well established and the operational costs are usually low compared with others.

Disadvantages (Dermont et al., 2008): 1) Requires large equipment and spaces for soil treatment; 2) The volume of soils to be treated must be large to be cost effective ( $>5000 \mathrm{t}$ for treatment on site); 3) Wash water treatment and off-site disposal of residual solids may be required what significantly increases the cost.

Chemical procedures

Advantages: 1) The sorbed metal forms can be treated; 2) Certain metal compounds can be dissolved; 3)The fine-grained soils may be treated in certain cases; 4) The extracted metals may be easily recovered by a wide variety of methods; 5) Chemically enhanced soil washing can become attractive if the chemical reagents are recycled, detoxified or not hazardous. (Dermont et al., 2008)

Disadvantages (Dermont et al., 2008): 1) The use of chemical agents significantly increase processing costs; 2) The processed soil may be inappropriate for revegetation and on-site disposal because the physic-chemical and microbiological properties have been affected; 3) The presence of toxic chemical agents in the final soil or the residual sludge may be problematic for disposal; 4) The presence of certain chemical agents in the wash fluid can complicate water recycling and treatment, thus increasing cost of the overall process; 5) The treatment of sludge rich in metal can be difficult; 6) The chemical agents involved may cause other environmental problems.

\section{Methods used for analyze of the fine fractions sampled}

According to the literature (Dermont et al., 2008; Mulligan et al., 2001) a combination of physical and chemical extraction should be done. The complementary use of both methods (physical particle separation and chemical leaching) can be a very useful tool for mining soils with a of metals presence. Thus, this combination should use physical separation (primarily by size, density or floatability properties) (Dermont et al., 2008) to concentrate particulate forms of metals into a small volume of soil, and then, it should be made combination of chemical extractions (with an appropriate methodology) to remove unwanted metals of that concentrated fraction (Mulligan et al., 2001).

\subsection{Högbytorp landfill, Bro, Sweden}

A test Landfill mining excavation was carried out on Ragn-Sells AB landfill site at Högbytorp, situated $40 \mathrm{~km}$ north-west of Stockholm during 2014. The Högbytorp landfill was established in 1964, occupies an area of around 30 ha and contains municipal as well as industrial wastes. The waste material excavated has been stored during 2009-2014 at Högbytorp as dispense from EU-directive. Sieve type TEREX model 883 (North Ireland) was used, a bucket excavator and a front loader.

Four test pits was excavated down to depth of 3.5-4 $\mathrm{m}$ in the landfill in order to get enough waste material (totally ca 2,100 tons) to make detailed characterization and heterogeneity of the waste to make a realistic mass balance and suggest a proper effective detailed sorting of 
Linnaeus ECO-TECH'14,

Kalmar, Sweden November 24-26, 2014

the waste masses for future full-scale excavation. In Fig. 6 the compositon of the waste fraction less $<40 \mathrm{~mm}$.

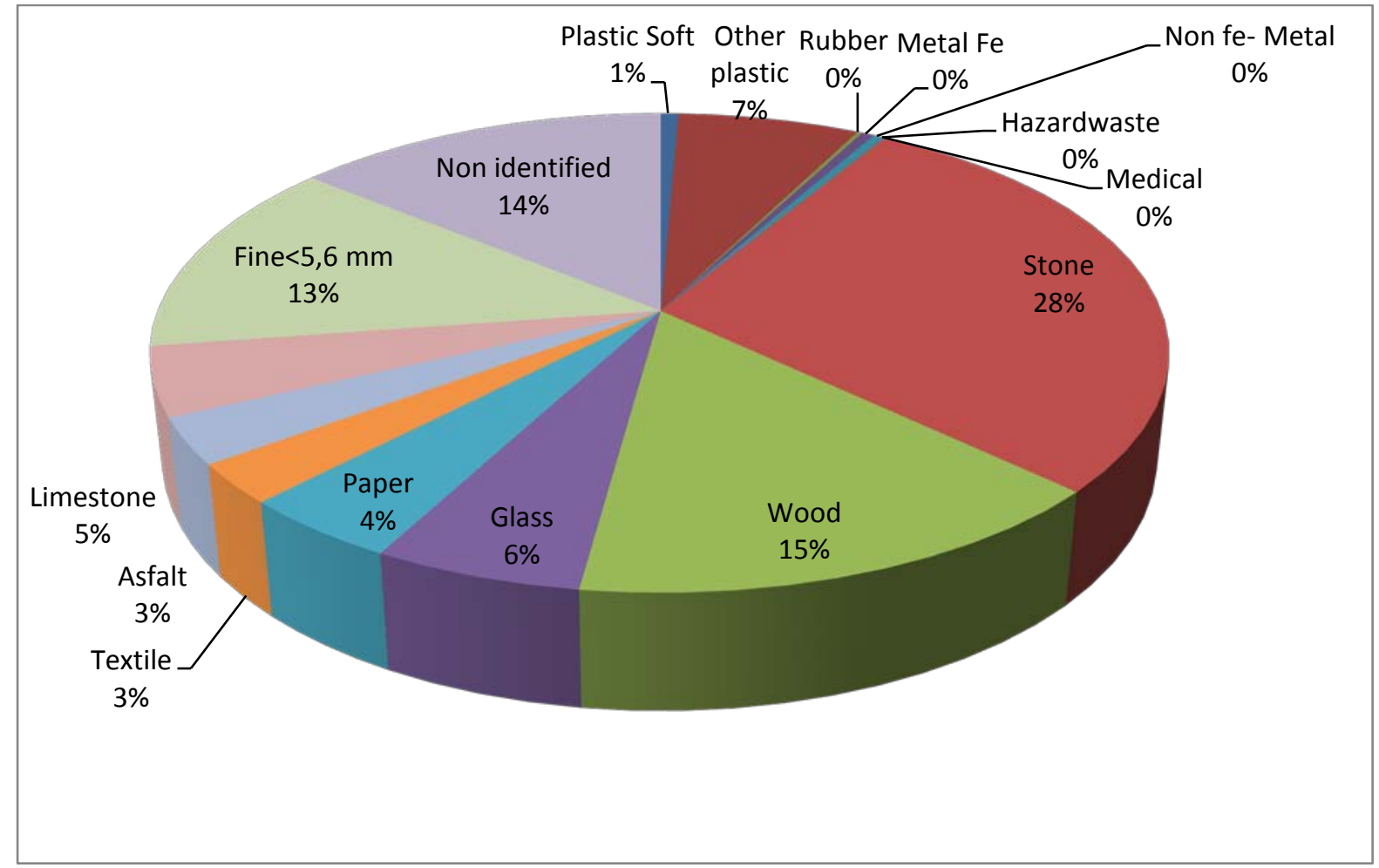

Figure 6. Characteristics of the waste fraction $<40 \mathrm{~mm}$, Högbytorp, Sweden.

The test excavation was performed during the dry summer in 2014 so no machinery problems were observed. The only problem was related to dusty roads and floating bitumen found in the waste mass. It is likely that an excavator with a bucket equipped with teeth has to be speed up and so facilitate excavation. In the full-scale excavation about ca 150,000-200,000 ton waste shall be excavated and there is permission to crush 18,900 tons of the coarse fraction. Wires, paint and bitumen and other types of waste can be found in the whole mass, also stones that should not go into the crushing machine Landfill mining causes extra damage on the machinery comparing to ordinary sorting works at the landfill. The extra damage costs are estimated to be $10 \%$ higher or $30 \mathrm{SEK} /$ ton (1/3 of a euro/ton). The sorting goes also slower than when making ordinary sorting. The question arises about how much of material must be re-landfilled after excavation and sorting. It is important to identify methods to separate metals, do waste picking analysis and washing of materials. If hazardous waste is found or generated the questions like; how should the waste be handled? What are the risks with moving materials around? Is the methane any problem for secure excavation? Must ventilation ditches be constructed or shall air blown into the landfill before excavation starts be used?

In the project the economics must be considered and include recovery of metals and waste fuels, soil etc. but the question is also if it possible to get back tax for masses that earlier been paid when landfilled? 


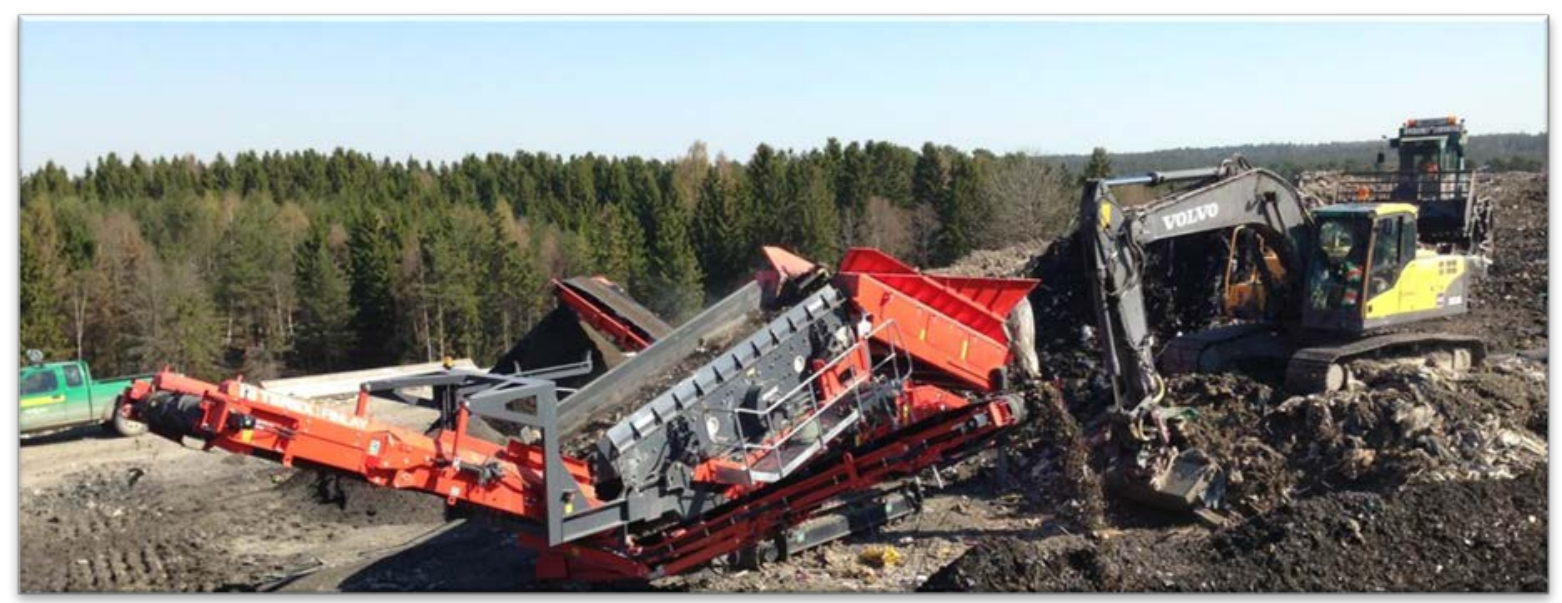

Figure 7. Sieving machine, bucket excavator and front loader used at Högbytorp.
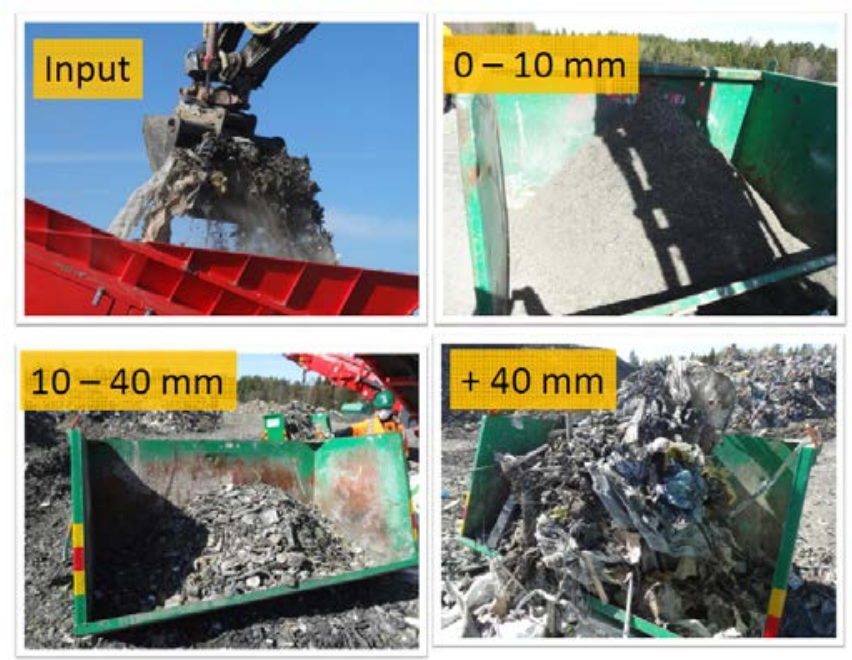

Figure 8. Pictures showing the different fractions ( $<40 \mathrm{~mm}$ fine fraction, $10-40 \mathrm{~mm}$ medium fraction and $>40 \mathrm{~mm}$ coarse fraction to be crushed) separated out.

The $>40 \mathrm{~mm}$ coarse fraction sorted was 392 tons in total - it was crushed in a coarse fraction shredder and then separated into a rest fuel fraction of 300 tons that contains ferrous metals as well as into 92 tons of a fine fraction $<20 \mathrm{~mm}$.. The separated medium fraction of size 10-40 mm was roughly estimated as to be 560-600 tons and the fine fraction 0-10 mm - 929 tons.

\section{CONCLUSIONS}

The right type of machinery must be selected for the type of waste landfilled through lifetime of a landfill. Also the combination of machineries is of importance, if these are on wheel or are band crawlers. Logistics in the working area is of importance for the economy as well as for keeping up withthe time schedule. Waste in the landfill can be made loose from the different waste layers by pushing it by heavy compactor but avoid this step because it gives extra work. It means 2-step excavating and this kind of sorting unit does not move the waste 
into the sorting machine. The seasonal weather conditions also affect the speed of work, safety issues and economy. Snow and muddy weather make it slippery and ground soft. The sieving is then made more difficult because of clogging and in general the work goes slower. Some types of waste give problems in the machines and conveyer belts as fishermen's net and long plastic ribbons. Other difficult items to handle are: fish nets, ropes, matrasses, textile tents, concrete blocks and big stones. Cold weather is preferred and the work proceeds much faster. Summer conditions are usually good but working process and transportation might be dusty. It might be necessary to sprinkle waste and transportation roads with water. Opening a landfill and removal of top layer requires large machines but after opening smaller excavator may take over easily. The working conditions might be dangerous for workers close to the machines and also for driver when for instant the excavator is balancing on the edge of the working face. In general the working face should be kept small to reduce dust, wind spreading of waste, smell and leachate/stormwater generation during rainfall. The sorted waste and recovery masses must be stored and handled properly. Stockpiling of excavated material is critical as it requires space and water vapour is a problem during very cold weather. Usually wind solves the vapor problem. However, in some piles of material in particular when containing organics the temperature rises fast to $60-70^{\circ} \mathrm{C}$ and there is a risk for self ignition during windy conditions. Explosive methane gas and explosive items, dust, chemical dust, aerosols, water vapour in large amounts gives problems. Hazardous waste might be found and must be stored and transported proparly. Transportion in hazardous materials in open bucketloads of waste by excavator and frontloader should be avoided. Machinery for sorting of the coarse fractions have been developed in the waste management but there is still a big need for separation of metals and nutrients from the fine fractions. From the scientific point of view there are some methods described in the literature for removing metals (from each group of metals) from soils and sediment with the aim to reduce costs, and considering environmental aspects. Various technologies and combination of methods are being developed and implemented for the remediation of soils and sediments contaminated with heavy metals. However, the removal of metals (toxic or not) bound to the soil is still a problem nowadays. In order to get very good economics of landfill mining, slag, sludge and sediment recovery new environmentally friendly economic methods need to be developed. The methods used today for separation of daily generated waste in society have taken 30 years or more to compile and are now go into a new period of more sophisticated sorting which might take another 30 years to be efficient in all respects.

\section{ACKNOWLEDGEMENTS}

The Swedish Institute gave financial support to the most important project "Closing the Life Cycle of Landfills - Landfill Mining in the Baltic Sea Region for future” related to the beyond the zero waste concept. The European Cohesion Fund and the Estonian Environmental Investment Centre participated contributed with funds to an excavation project in Estonian gathering researchers from 7 countries.

\section{REFERENCES}

Dermont G., Bergeron M., Mercier G., Richer-Laflèche M. Soil washing for metal removal: a review of physical/chemical technologies and field applications. J Hazard Mater. v. 152, n. 1, 31 p. 2008 
Ghirişan A.L., Drăgan S., Pop A., Simihăian M., Miclăuş V. Heavy Metal Removal and Neutralization of Acid Mine Waste Water - Kinetic Study. The Canadian Journal of Chemical Engineering. v. 85, 2007

Hogland W., Marques M., Nimmermark S. Landfill mining and waste characterization: a strategy for remediation of contaminated areas. J Mater Cycles Waste Manag. v. 6, 119-124p. 2004

Hogland, W. Remediation of an old landfill: soil analysis, leachate quality and gas production. Environmental Science \& Pollution Research International. v. 1, 49-54p. 2002

Joseph, K., Nasgendran, R., Thanasekaran, K., Visvanathan, C., Hogland, W., Kathikeyan, O., P., Moorthy, N.N., 2008. Dumpsite rehabilitation manual, Centre for Environmental Studies, Anna University, Chennai - 600025 India

Kollikkathara N., Feng H., Stern E. A purview of waste management evolution: Special emphasis on USA. Waste management. v. 29, 974-985p. 2009

Krook J., Svensson N., Eklund M. Landfill mining: A critical review of two decades of research. Waste Management. v. 32, 513-520p. 2012

Mulligan C.N., Yong R.N., Gibbs B.F. Heavy metal removal from sediments by biosurfactants. Journal of Hazardous Materials. v. 85, 111-125p. 2001

Salerni, 1., E. Landfill Reclamation Manual. Reclaim-95 Landfill Mining Conference, September 28-29, 1995, Resource Recovery Report, SWANA Landfill Reclamation Task Group.1995

Zhao Y., Song L., Huang R., Song L., Li X. Recycling of aged refuse from a closed landfill. Waste Management Research. v. 25, 130-138p. 2007 